\title{
La evolución de la construcción del Templo de la Sagrada Familia
}

\section{The evolution of Sagrada Familia construction}

\author{
$\underline{\text { R. Espel }}{ }^{(*)}$, J. Gómez ${ }^{(*)^{(* *)}}$, R. Grima ${ }^{(* *)}$, A. Aguado ${ }^{(* *)}$
}

RESUMEN

El Templo de la Sagrada Familia (Barcelona, 1882-hoy) es, aun inacabado, una de las obras más importantes de Gaudí y uno de los máximos exponentes de la arquitectura modernista catalana. Este artículo hace un recorrido en la evolución de la construcción del Templo, haciendo hincapié en los retos constructivos que han supuesto las formas de Gaudí.

A lo largo de la historia los materiales se han adaptado a las necesidades de cada parte a realizar. A finales del s. XIX, Gaudí empezó construyendo principalmente a base de mampostería tradicional, pero dedicó años al estudio del resto del Templo y a los diferentes materiales con los que podía construirse. El texto continúa describiendo cómo los colaboradores de Gaudí siguieron las obras tras su muerte y cómo, en los últimos años, se han introducido en el Templo los últimos avances en los procesos constructivos y en los materiales. Buen ejemplo de ello son los hormigones de prestaciones especiales utilizados en la actualidad y las técnicas de dibujo asistido por ordenador más avanzadas del mercado.

$148-169$

Palabras clave: Gaudí, Sagrada Familia, construcción, evolución, materiales.

\section{INTRODUCCIÓN}

La Sagrada Familia es el Templo religioso iniciado por el arquitecto modernista catalán Antoni Gaudí y que lleva construyéndose
SUMMARY

Despite its unfinished state, the Temple of the Holy Family, or Sagrada Família, is Antoni Gaudís most widely recognized work and one of the most important milestones in the development of Catalan Modernism. This article follows and describes the evolution of the construction of the temple, highlighting the challenges which it has faced when searching for viable constructive solutions for Gaudi's architecture.

Throughout history the construction materials have been adapted to the needs of each of the elements which had to be built.

Although, at the end of S. XIX, Gaudí built mostly in traditional masonry, he spent years studying the rest of the Temple and the different materials that could be built. This text continues to describe as collaborators of Gaudi's work could continue the construction after his death and how, in recent years, recent advances in constructive processes and materials have been introduced in the Temple. This continuous innovation process can be exemplified by the concrete used for special tasks at present or the cutting-edge Computer Assisted Design techniques which aid in the construction process.

Keywords: Gaudí, Sagrada Familia, construction, evolution, materials.

más de un siglo (desde 1882) en el centro de Barcelona. Pero la obra, aunque ha ido evolucionando a nivel de esculturas y acabados, sigue los principios inspiradores del proyecto estructural original de Gaudí, al

\footnotetext{
(")Miembros del equipo técnico de la Junta Constructora del Templo de la Sagrada Familia

${ }^{(* *)}$ Universidad Politécnica de Cataluña (UPC), Cataluña (España). Actuales colaboradores de la Junta Constructora del Templo de la Sagrada Familia
} 
que se dedicó a tiempo completo desde 1914 hasta su muerte en 1926. Desde el principio, esta dedicación se refleja en los modelos de yeso de las columnas, las naves, las fachadas, etc. y en las enseñanzas que supo transmitir a sus colaboradores para dar continuidad a las obras.

La labor constructiva de estos colaboradores (Puig Boada, Bonet Garí, Sugrañes, Quintana, Ràfols, Folguera, Bergós y Martinell, entre otros) a lo largo de más de 80 años, continúa siendo bastante desconocida. A menudo se ha visto tapada por el estudio de la forma, el simbolismo de la obra y la figura del propio Gaudí (1). También ha influido la polémica de la conveniencia de continuar o no las obras, que ya vivió Gaudí durante la época noucentista y que, si bien ya no es tan viva como hace años, sigue teniendo ciertas brasas que coyunturalmente avivan la polémica. Como muestra histórica cabe reflejar las palabras de Pla en 1969.

"Cuando llegué a Barcelona en 1913 para estudiar en la universidad, quedé sorprendido de la indiferencia de los estudiantes - casi todos de familia burguesa- ante la obra (de la Sagrada Familia). Después, y ya más o menos en contacto con los medios intelectuales, afirmar que encontré indiferencia es decir poco. Constaté una oposición abierta, deliberada y consciente. Era el triunfo del noucentismo. La bestia negra de Eugeni d'Ors fue Gaudí" (2).

Con este artículo se pretende hacer un análisis histórico de la construcción de la Sagrada Familia a través de la evolución de sus materiales, haciendo hincapié en cómo los avances técnicos han permitido superar muchas de las necesidades constructivas surgidas a lo largo de los años y cómo los

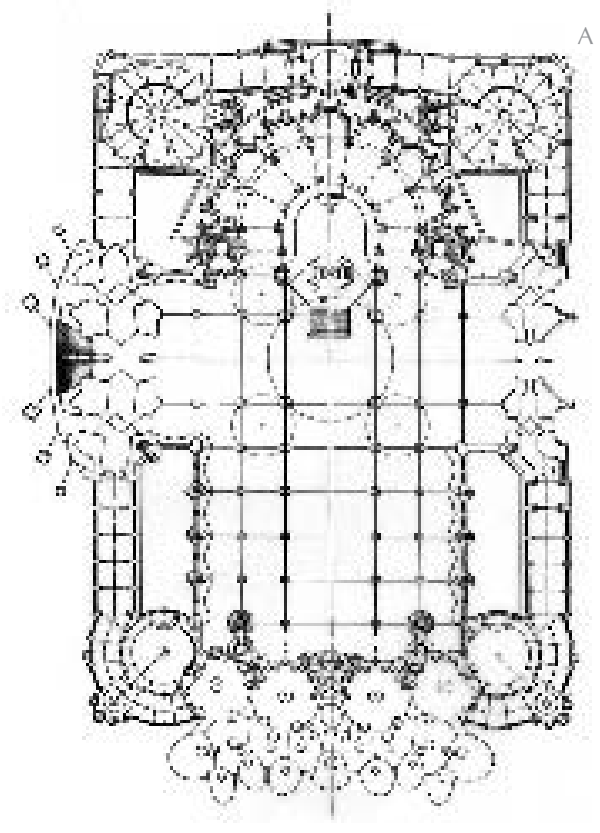

diferentes directores de las obras han ido dando respuesta a las necesidades de cada uno de los problemas planteados. También señalaremos las diferencias entre la aparición de los avances técnicos en el sector de la construcción y su incorporación definitiva en la Sagrada Familia. En cualquier caso, cabe señalar que el espíritu impuesto por Gaudí a la concepción de la obra se mantiene a lo largo de los años a través de la Junta Constructora actual heredera de la que empezó las obras a finales del s. XIX.

\section{EL TEMPLO DE LA SAGRADA FAMILIA. DESCRIPCIÓN}

La originalidad y todo aquello que significó el trabajo de Gaudí en cuanto a innovación dentro del mundo de la construcción está presente en la obra de la Sagrada Familia. Pero, para poder entender el trabajo realizado, en primer lugar es necesario hacer una breve descripción del Templo.

La Sagrada Familia tiene una planta clásica en cruz latina, con cinco naves longitudinales y un crucero de tres, un ábside y una cripta bajo el altar principal, tal como puede verse en la figura 1A. El Templo tendrá en el futuro tres fachadas. El pórtico principal, situado a los pies del fuste, Ilamado de la Gloria, simbolizará la resurrección de Jesucristo. Las otras dos entradas, ya construidas, están situadas en los extremos del transepto y están dedicadas al Nacimiento y a la Pasión de Cristo. Cada puerta contará con cuatro torres. El conjunto estará rodeado por un claustro rectangular.

Además, seis grandes torres coronarán la estructura sobre las cubiertas del crucero y el

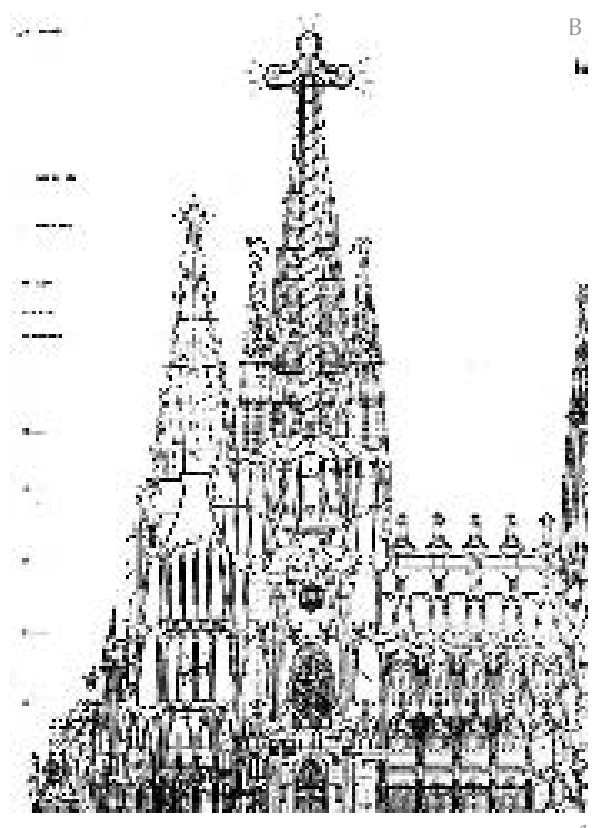

(1) La planta del Templo que se adjunta es una copia actual de la primera planta publicada en 1929 por Isidre Puig Boada (4).

(2) El perfil del Templo que se adjunta corresponde a la versión dibujada en 1974 por J. Berenguer.
1. Planta (A)1 y Perfil virtual (B)2 del Archivo del Templo Expiatorio co del Templo Expiatorio Archivo gráfiFamilia (en adelante ATESF). 
ábside dedicadas a los evangelistas, a Cristo y a la Virgen María, tal como se muestra en la figura $1 \mathrm{~B}$.

Para Gaudí, forma y estructura están unívocamente relacionadas. Buen ejemplo de ello son las formas geométricas de la Sagrada Familia a las que dedicó la investigación de los últimos años de su vida.

"Si analizamos desapasionada pero pausadamente la obra de Gaudí desde la óptica de la construcción, comprobaremos cómo es de falaz afirmar que aquella arquitectura se concibió olvidándose que debía ser construida. Bien al contrario, detrás de cada forma nueva late una búsqueda inquieta de una solución constructiva" (González Moreno-Navarro, 1990) (3).

Gaudí dedicó una parte importante de su trabajo a la investigación estructural. Analizó la disposición estructural de los Templos construidos hasta ese momento y los elementos de la naturaleza buscando racionalizar las formas arquitectónicas para que se adaptasen mejor a la distribución de fuerzas. Para ello, Gaudí introduce en la Sagrada Familia numerosas superficies regladas (hiperboloides, paraboloides, elipsoides elípticos...) que formarán la mayoría de los elementos del Templo (desde ventanales hasta cubiertas) y que constituyen una de sus singularidades más importantes pudiendo transmitir mejor las cargas que las bóvedas nervadas góticas por poner un ejemplo. Por otro lado, el diseño de estas formas regladas a base de figuras geométricas exactas, sistemáticamente repetitivas, pueden ser construidas en la actualidad a pesar de la ausencia de planos. Se puede consultar una descripción más exhaustiva en el libro El templo de la Sagrada Familia, de uno de los ayudantes de Gaudí, Isidre Puig Boada (4).

Este planteamiento permite cierto nivel de industrialización y en cierta medida nace como respuesta, desde el punto de vista económico, para hacer posible la plástica de Gaudí al utilizar de forma sistemática superficies regladas que pueden prepararse con unos menores costes de encofrados (5). En la tabla 1 (pág. siguiente) se muestran los periodos principales de las obras, los cuales se han dividido en tres (el constituido desde el principio de la obra a la muerte de Gaudí, las obras de sus discípulos directos y el periodo de arquitectos directores que ya no conocieron a Gaudí en vida). En dicha tabla se presentan, asimismo, las actuaciones realizadas en estos periodos y los directores implicados en cada uno de ellos. En ella puede apreciarse que el volumen principal de obra se ha realizado en los últimos 25 años.
A lo largo de los más de ciento veinticinco años de construcción, las circunstancias económicas, sociales y tecnológicas han variado mucho. En este contexto, las obras de la Sagrada Familia son un buen exponente de esa evolución, incorporando las nuevas técnicas de proyecto y construcción en la misma, a veces con pequeños retrasos sobre el inicio de la innovación correspondiente. A manera de ejemplo, el hormigón de alta resistencia empezó a utilizarse en España a principios de los años 90 (6), pero no se utilizó de forma habitual en la construcción de la Sagrada Familia hasta 1998, algo similar pasa en la actualidad con el hormigón autocompactante.

\section{EVOLUCIÓN DE LOS MATERIALES}

\subsection{Construcción tradicional. Mampostería y piedra}

Las obras de la Sagrada Familia se inician, tal y como se ha dicho en la tabla 1, bajo la dirección del arquitecto Francesc de Paula Villar en 1882. Al año siguiente lo sucede Gaudí que dirige las obras hasta su muerte en 1926. En aquel momento se había iniciado la construcción de las primeras columnas de la cripta. Gaudí mantiene las partes ya construidas por Villar pero replantea el proyecto del Templo de una pequeña Iglesia a un gran Templo neogótico que finalmente no tendrá contrafuertes (figura 2, pág. 9).

Los materiales utilizados durante estos primeros años fueron sobre todo pétreos (sillería de Montjuic y Vilafranca con relleno de mampostería) y las técnicas constructivas eran básicamente tradicionales. Hasta el momento las grandes construcciones se realizaban en piedra como en la antigüedad y las edificaciones más normales (de menores solicitaciones estructurales) en ladrillo.

El conglomerante más habitual durante todo este periodo fue la cal (principalmente hidráulica). El uso de este ligante fue muy popular en España hasta bien entrado el s.XX después de que en 1791 Louis Vicat (Francia) y James Parker (Inglaterra), con la cocción de cal grasa y arcilla, empezaran a desarrollar diferentes tipos de cal hidráulica. Este haIlazgo les permitió tener una alternativa a la cal aérea tradicional. Con este material muy probablemente se construyó la cimentación de la cripta y de la Fachada del Nacimiento en la Sagrada Familia.

En los últimos testigos extraídos ${ }^{(3)}$ de las columnas de la cripta (1884-1887) se han hallado restos de ladrillería en el interior de las piezas exteriores de piedra natural. Más adelante, los muros de la Fachada del Naci-
(3) En la actualidad se está realizando el refuerzo de la cimentación de la cripta y se han extraído testigos de las columnas existentes. 
Tabla 1

Plantas de la Sagrada Familia con los elementos construidos durante los distintos periodos y los directores de las obras. Fuente: ATESF.

\begin{tabular}{|c|c|c|c|}
\hline Período & Esquema & Elementos & Directores \\
\hline $1882-1926$ & & $\begin{array}{l}\text { - Cripta } \\
\text { - Muros absidiales } \\
\text { - Fachada del Nacimiento }\end{array}$ & $\begin{array}{l}\text { Francesc de } \\
\text { Paula Villar } \\
1882 \\
\text { Antoni Gaudí } \\
1882-1926\end{array}$ \\
\hline 1927-1982 & & $\begin{array}{l}\text { - Columna Barcelona } \\
\text { - Fachada de la Pasión } \\
\text { - Ventanales de la fachada } \\
\text { de la Pasión }\end{array}$ & $\begin{array}{l}\text { Doménec } \\
\text { Sugranyes } \\
(1927-1936) \\
\text { Francesc } \\
\text { Quintana } \\
\text { (1939 - 1966) } \\
\text { Isidre Puig Boada } \\
\text { (1966 - 1974) } \\
\text { Lluís Bonet Garí } \\
\text { (1971 - 1983) }\end{array}$ \\
\hline $\begin{array}{c}\text { 1983- } \\
\text { actualidad }\end{array}$ & & $\begin{array}{l}\text { - } \text { Muros perimetrales } \\
\text { - Columnas y cubiertas de } \\
\text { las naves (cuerpo } \\
\text { principal, transepto y } \\
\text { ábside) } \\
\text { - Cimentación y columnas } \\
\text { de la fachada de la Gloria } \\
\text { - Claustro } \\
\text { En la actualidad se están } \\
\text { iniciando las torres que } \\
\text { coronarán el crucero }\end{array}$ & $\begin{array}{l}\text { Francesc . } \\
\text { Cardoner } \\
(1983-1985) \\
\text { Jordi Bonet i } \\
\text { Armengol } \\
(1985-)\end{array}$ \\
\hline
\end{tabular}

miento (a partir de 1894) se construyeron en su parte de mampostería con piedra de Montjuïc unida con mortero de cal. Incluso la losa de cimentación de esta fachada, que en 1895 llegaba hasta once metros de profundidad, se realizó con grandes bloques de piedra unidos con cal. Autores como Bassegoda i Nonell (ex director de la cátedra Gaudí) consideran que la singularidad de la obra en estos años, teniendo en cuenta la tipología de materiales disponibles, es uno de los grandes logros de Gaudí

"El principal mérito de Gaudí es el de haber creado formas inéditas utilizando los materiales y las técnicas tradicionales. Por esta razón la arquitectura de Gaudí es intemporal, pudiendo haberla hecho tal cual en el siglo XIV o en los siglos futuros." (7).

Como justificaremos a partir del apartado siguiente, nuestra opinión es que la obra de la Sagrada Familia fue planteada desde el principio para ser construida incorporando los avances técnicos de los materiales del siglo XX.

\subsection{Los inicios del hormigón armado}

El final del siglo XIX fue una época de grandes innovaciones en la construcción. En Europa, al abrigo de las exposiciones universales, aparecen nuevos materiales. Se diseñan grandes construcciones metálicas y empieza a desarrollarse la industria del hormigón.

Así con posterioridad al descubrimiento del cemento Portland, se empezó a ensayar con hormigón armado. Los primeros resultados aplicables en vigas y otros elementos estructurales fueron explotados a partir de patentes. En 1892 y 1893 fueron creadas las dos grandes compañías europeas de 
construcción con la técnica del hormigón armado: "Hennenbique" (Francia) y "Ways und Freutag" (Alemania) (8).

Con cierto retraso la tecnología llegó a España y a Cataluña, en este caso de la mano de Francesc Maciá, que posteriormente sería presidente de la Generalitat de Catalunya (9), que en 1893 compró los derechos de explotación de la patente Monier para la realización de las obras del ferrocarril del valle del Noguera Pallaresa y, más tarde, formó parte de la empresa del arquitecto Claudi Durán que construía obras con este sistema.

Poco a poco el hormigón deja de ser un material exclusivo de las obras públicas. El primer edificio construido con este material se considera que fue el $n^{\circ} 95$ de la calle Franklin en París, obra de Gustave i Auguste Perret en 1901.

En el contexto catalán, la primera cementera la fundó Eusebi Güell (Castellar de N'Hug, 1904), en 1901 a través de la compañía Asland de fabricación de cemento Portland (la figura 3 reproduce un cartel de la época donde la fotografía empleada es el parque Güell, también de Gaudí), influido por los sucesores de Rafael Gaustavino que habían emigrado a Estados Unidos para poder construir bóvedas de ladrillo con mortero de cemento en el interior (10). Cataluña vivía un proceso de industrialización donde parte del capital repatriado tras la pérdida de las colonias (Cuba y Filipinas) volvía a invertirse en nuevas industrias del país. Cabe recordar que Güell era gran amigo y mecenas de Gaudí. Por este motivo, el arquitecto entra en contacto con el nuevo material y lo empieza a utilizar de forma puntual en algunas de sus obras, como es el caso de las vigas de los pabellones del Parque Güell (11), tal como se muestra en la figura 4, pág. siguiente.

Hay que tener presente que en Cataluña la arquitectura modernista se encuentra a principios de siglo en pleno apogeo, sus construcciones basadas en el ladrillo hacen que la introducción del hormigón se retrase. Joaquim Bassegoda i Amigó (1925) (12) explica, en una conferencia en el Colegio de Arquitectos de Cataluña, la falta de utilización de este material en Cataluña. Según su opinión no es por rutinarismo como mantienen otros autores sino porque el hormigón, que se presenta como una alternativa más barata, no es tan competitivo frente a las optimizadas técnicas tradicionales catalanas.

Entre las primeras obras de hormigón de las que se tiene constancia se encuentran los tinglados de la Barceloneta en el Puerto

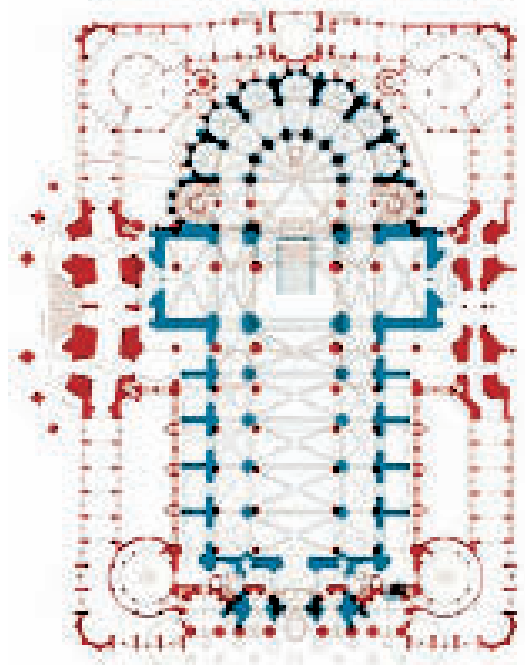

1882 projecte de Francesc de Paula del Villar 1883-1926 projecto d'Antoni Gnudi

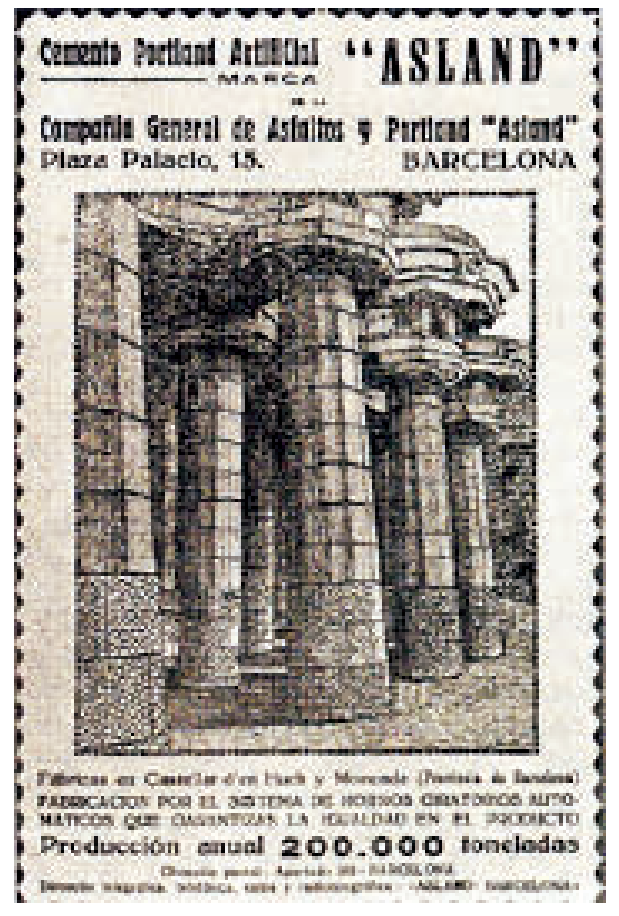

de Barcelona que Eugenio Ribera diseñó en 1906 y un depósito de agua, todavía existente, de $300 \mathrm{~m}^{3}$ en Sabadell obra del arquitecto Luís Homs Moncusí construido en 1915. Esta torre de agua, ya fuera de servicio, ha sido catalogada y forma parte del patrimonio industrial de Cataluña. En edificación, fueron numerosas las construcciones de hormigón armado que se prepararon para la exposición de 1929. Entre ellos se encuentra el Palacio Nacional obra del arquitecto Cendoya y actual sede del Museo Nacional de Cataluña (8).

Pero, ¿cuándo empieza a utilizarse el hormigón en la Sagrada Familia? Este material, está
2. Planta de la iglesia proyectada por el arquitecto Villary la primera versión del proyecto de Gaudí, superpuestas ${ }^{(4)}$ Fuente: www.sagradafamilia.org

3. Cartel ASLAND. Fuente: ATESF.
(4) La planta corresponde al último proyecto del arquitecto $\mathrm{Vi}$ Ilar para el Templo de la Sagrada Familia (1882). Al año siguiente Gaudí replantea el proyecto a partir de la planta adjunta (planta publicada en 1929 por Isidro Puig Boada (4). 
4. Vigas de los pabellones del Parque Güell. Fuente: (Bergós Massó, 1953) (11).
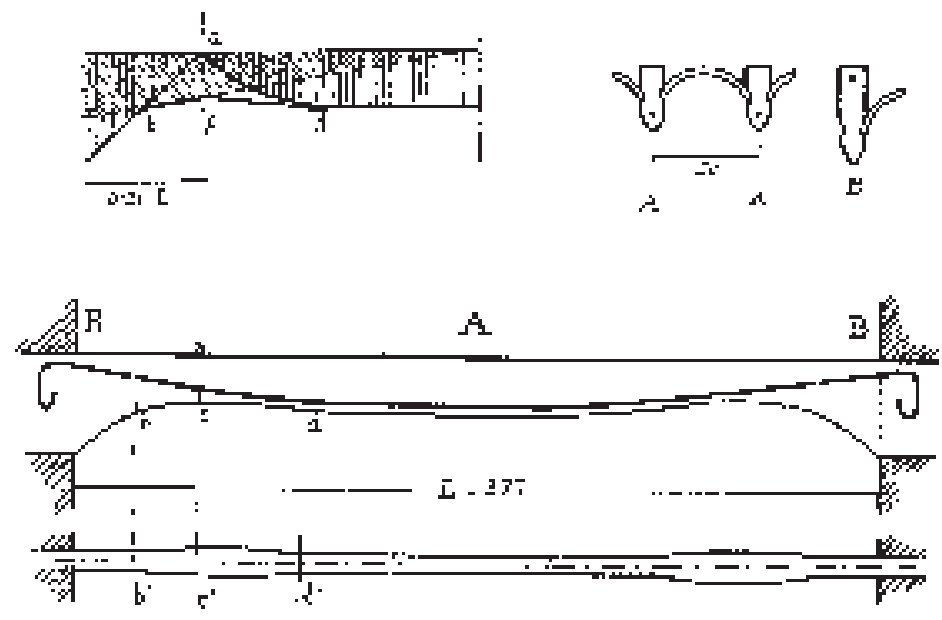

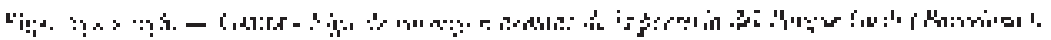

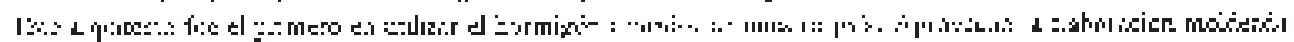

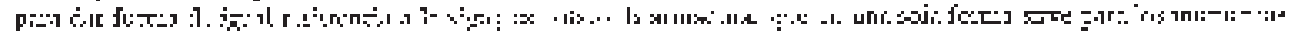

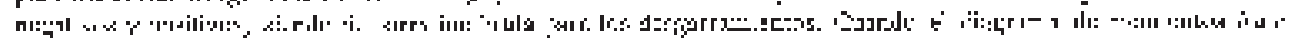

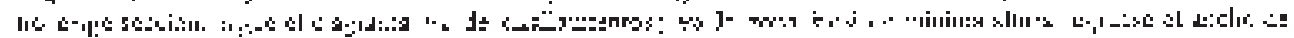

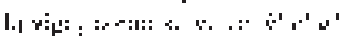

presente, con seguridad, en la parte final de las torres de la Fachada del Nacimiento (1915 y 1934), pues así lo demuestra el resultado de los ensayos realizados en la torre de San Bernabé en enero de 1997 por el departamento de mineralogía de la Universitat de Barcelona y el consultorio de química Lend Consulting (13). Esto demuestra que Gaudí se interesó y utilizó en vida los nuevos materiales (14).

Estos cuatro campanarios de las torres de la Fachada del Nacimiento (ver figura 5) terminan en unos pináculos de 24,6 m construidos con un núcleo de hormigón armado. Además, las piezas exteriores de los últimos $17 \mathrm{~m}$ de coronación que están recubiertas de cristal de Murano son de hormigón armado prefabricado en los talleres del Templo. Esta forma de industrialización in situ se ha mantenido en el tiempo si bien en los últimos años se ha externalizado parte de la misma.

Podría parecer que el hormigón tiene en estos elementos el mismo carácter que en las primeras obras de Gaudí (donde mayoritariamente tenía un papel decorativo). No es así, las piezas prefabricadas de estos pináculos miden más de 3 metros y están colocadas a más de 100 m de altura lo que hace que sea necesario construirlas con un material capaz de resistir las tracciones que pueden presentarse tanto en la manipulación como en la configuración final, frente al viento.

Su respuesta a este reto es el empleo del hormigón armado. Así se construyó el pináculo de San Bernabé, 1926 (el único que vio acabado Antoni Gaudí ) y así se construyeron el resto de los que coronan la fachada del Nacimiento (finalizada en1930) y los que coronan la fachada de la Pasión (finalizada en 1977).
Con el tiempo la mayoría de las formas del Templo han resultado adecuadas para ser realizadas con hormigón armado. Pero, dado que este material ya se conocía (y utilizaba en vida de Gaudí) podemos preguntarnos cuál fue su actitud frente a su empleo en el Templo o por qué no lo utilizó más. ¿La razón del retraso en la introducción, de forma generalizada, de estos cambios hay que buscarla en las dificultades económicas que implicó el cambio de siglo y que ralentizaron la construcción o en una apuesta del arquitecto por la construcción tradicional? En las primeras décadas del s.XX, Gaudí aprovechó el bajo ritmo de las obras para trabajar en el diseño de diferentes partes del Templo. Trabajó en el boceto de la fachada de la Pasión y la Gloria, pero especialmente en la maqueta del interior del Templo.

El planteamiento de Gaudí era racionalizar las estructuras mejorando aquellos detalles constructivos que, según él, hacían vulnerables las construcciones góticas, conjugando los materiales con la forma de trabajar de la estructura. Intentaba suprimir los elementos indispensables cuyo colapso supondría la ruina del edificio. Para ello, propuso eliminar los contrafuertes exteriores y resistir los empujes horizontales de las cubiertas diseñando las columnas interiores ramificadas a cierta altura tomando la inclinación de las cargas (15).

Además, decidió que las bóvedas formasen un cuerpo monolítico buscando una estructura hiperestática capaz de resistir la desaparición de algunos de sus elementos (arcos o columnas). Esto se traduce, por un lado, en el planteamiento de los techos a base de hiperboloides y, por otro, según documentan los colaboradores de Gaudí (16), 


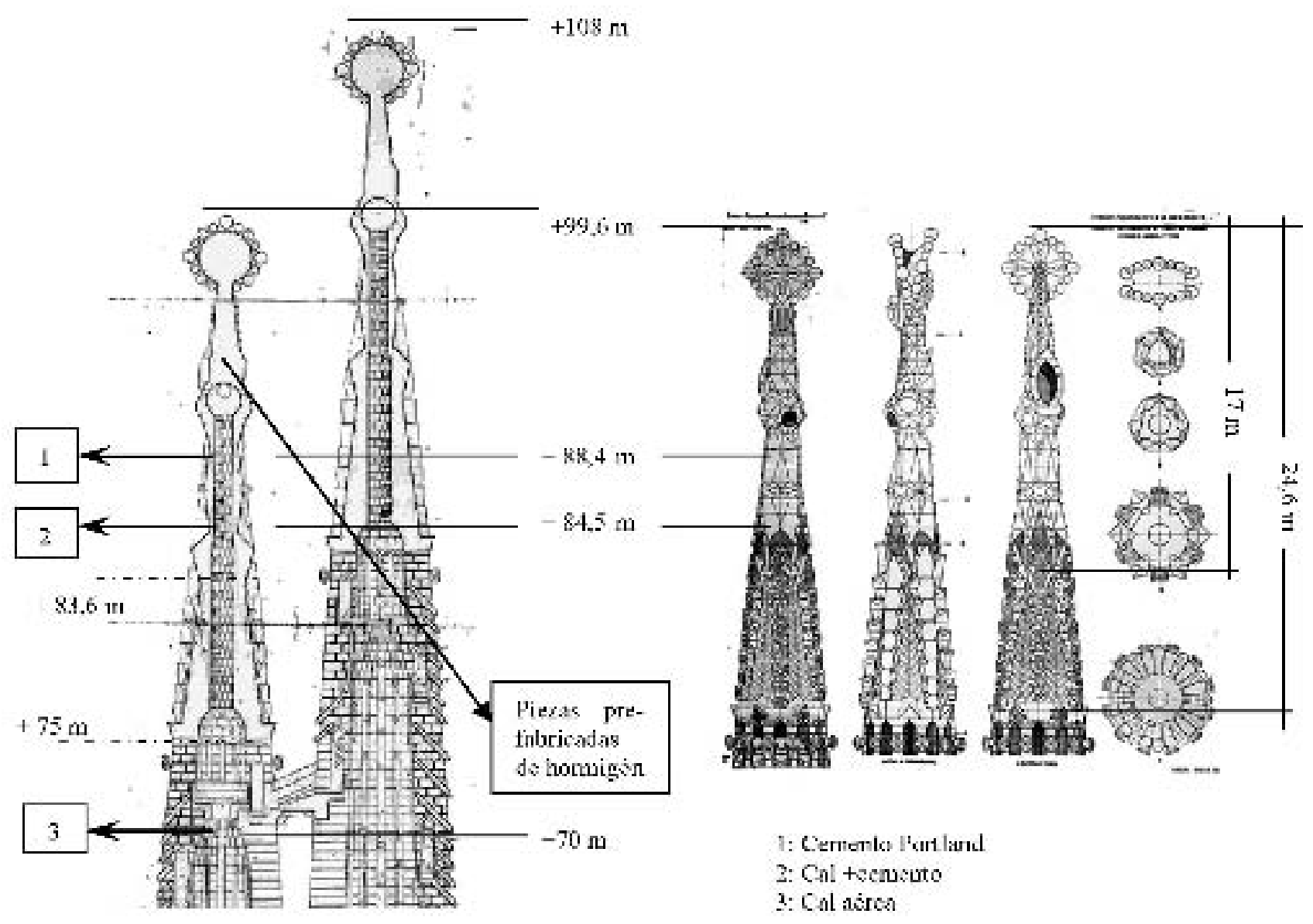

éste ya plantea en sus estudios la idoneidad de construir la bóvedas con hormigón armado (concrecionado, como el decía). Un material que puede adquirir cualquier forma dándoles a las cubiertas el carácter de estructura unitaria que pretendía.

Alrededor de la Sagrada Familia aparece de forma reiterada la pregunta de si se podría haber construido con los materiales con los que trabajaba Gaudí o si es realmente necesario el empleo del hormigón armado. Para los autores de este artículo, la realidad es muy diferente y es necesario replantear la pregunta. ¿Cuáles fueron realmente los materiales utilizados por Gaudí? ¿Cómo imaginó las partes del Templo que ya sabía que no vería construidas?

Los siguientes apartados desarrollaran la idea de que Gaudí diseñó para la Sagrada Familia unas formas adaptadas a una distribución de las cargas diferente a los Templos construidos hasta entonces para que pudiesen ser construidas, tanto con materiales tradicionales, como con las nuevas técnicas constructivas que empezaban en aquel momento.

\subsection{Generalización del uso del hormigón}

Tras la muerte de Antonio Gaudí (1926) Domenech Sugranyes continuó las obras hasta
1936. Una vez finalizada la Guerra Civil otros tres de los colaboradores directos de Gaudí (Isidre Puig Boada, Francesc Quintana y Lluís Bonet Garí) dirigieron las obras de la Sagrada Familia tal como se muestra en la citada tabla 1. Ellos continuaron las obras a pesar de ciertas dificultades económicas y de que el incendio del taller en 1936 había acabado con la mayoría de los planos y estudios. No obstante, se salvaron las maquetas que han permitido seguir las obras contando con una gran implicación por parte de todos los arquitectos y la búsqueda de la innovación constructiva.

Entre 1939 y final de los años 50 sólo se realizaron trabajos de limpieza y restauración. Durante estos años la construcción estuvo condicionada por la crisis mundial después de la II Guerra Mundial y la Guerra Civil Española. La difícil situación económica limitó mucho el avance de las obras.

¿Cómo pudo recomponerse la información destruida en el incendio de 1936 hasta poder decir que se ha continuado con el proyecto de Gaudí? Dos cuestiones fueron de gran importancia, por un lado, la información de la que disponían los colaboradores de Gaudí que se encargaron de plasmarla en las primeras biografías y escritos sobre su obra $(4,14,15$ y 16). Como ya se ha comentado
5. Alzado del pináculo de San Bernabé en la Fachada del Nacimiento. Fuente: ATESF. 
alguno de ellos fueron los que le relevaron en la construcción del Templo. Por otra parte, Gaudí trabajó mucho con maquetas de yeso escala 1:10 y $1: 25$ que, aunque destrozadas, sobrevivieron al incendió. Se dispone de modelos de los claustros, las sacristías, las torres de las fachadas, además de secciones y alzados de conjunto que pudieron recomponerse gracias a planos y fotografías salvados de las llamas.

Es innegable, por otra parte, que a partir de la muerte de Gaudí, decisiones sobre acabados, encuentros entre estructuras, detalles y decoración han sido tomadas por generaciones posteriores. Pero Gaudí dejó determinada la volumetría general del Templo con las plantas y los alzados definidos, además de dibujos de las entradas.

Al reanudarse los trabajos hacia la segunda mitad de los años 40, el hormigón había revolucionado el mundo de la construcción, convirtiéndose en el material habitual de las obras. El hormigón armado lejos de la época de las patentes, se convierte en una técnica universal que acaba desplazando a la construcción tradicional (9) y aparece una generación de ingenieros y arquitectos habituados al uso del nuevo material.

Gaudí entró en la Sagrada Familia para introducir el relleno en las columnas de la cripta y no la mampostería original. De la misma manera, con posterioridad, se sustituyó el relleno de piedras y caliza por el de hormigón ciclópeo. En la Sagrada Familia empezó a utilizarse hormigón en el relleno interior de grandes masas como substituto del mortero de cal. Se empleaba hormigón ciclópeo, un hormigón plástico al que después de extender la pasta se le añaden piedras de 20-30 cm (en un $30 \%$ ). En la figura 6 puede verse la construcción de la cimentación de la fachada de la pasión con este material. En ella se aprecia que el hormigón o mortero de recepción (no los bloques de piedras) se hacía con una pequeña hormigonera de unos 75 litros. Más adelante, alrededor de los años 60, el uso del hormigón se generaliza por su economía y sus prestaciones cuando se abandona la cal como

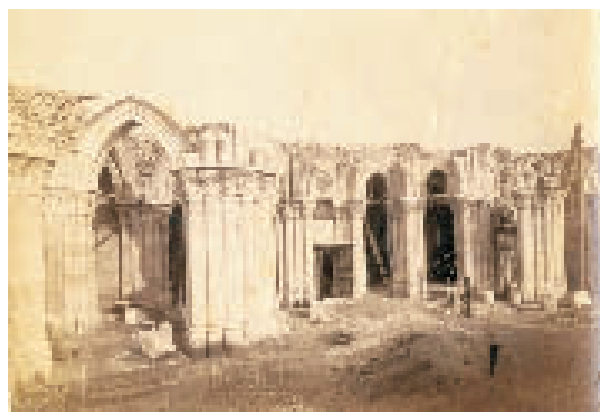

A conglomerante. Con la construcción de los muros perimetrales y la fachada de la Pasión la obra necesitaba todavía más un material económico para utilizar como relleno en los paramentos de piedra exteriores de paredes y fachadas. El hormigón ciclópeo era un material muy adecuado para estas necesidades. A nivel estructural, también empezó a utilizarse hormigón armado como material resistente en elementos como las columnas inclinadas de la puerta de la Pasión (ver figura 7), los pináculos que coronan la fachada o la losa de cimentación que se describe a continuación. El hormigón deja de usarse puntualmente y se convierte en un material habitual en las obras de la Sagrada Familia a partir de este momento.

Las seis columnas de la entrada de la Pasión, que empezaron a construirse en 1964, sostienen el voladizo del pórtico de entrada que, en su parte más alta, llega al tercer piso $(22,5 \mathrm{~m})$. Aunque la inclinación se corresponde con la de las cargas que ejerce el pórtico, para garantizar la estabilidad de las columnas durante todo el proceso constructivo se utilizó hormigón armado de la misma manera que en los pináculos o en las vigas de hormigón del Parque Güell. Necesitaban un material que resistiese parte de los esfuerzos a tracción durante la construcción cuando éstas estaban cimentadas al suelo y actuaban como una ménsula inclinada. Si se hubiesen planteado en piedra deberían haber sido estructuras monolíticas o haber contado con elementos de refuerzo mucho más costosos durante su construcción. En la losa de cimentación de la Fachada de la Pasión, uno de los elementos más singulares de la Sagrada Familia, fue la primera ocasión en la que se utilizó hormigón armado en grandes cantidades y de forma controlada. En el armado inferior de la losa se utilizó un emparrillado de raíles de tren -más de 4 km- donados por RENFE, entre 1954 y 1958. En la figura 8 se ven dichos raíles en la losa de cimentación citada.

El hormigón se fabricaba en los talleres del templo de forma manual y generalmente se hormigonaba in situ; no obstante en ele-
(B) en comparación con la cripta de la ATESF. 
mentos decorativos como en el recubrimiento de los capiteles de la fachada de la Pasión se utilizaron piezas prefabricadas preparadas en lo propios talleres, tal como se muestra en la figura 9. No es hasta el periodo siguiente que su fabricación se mecaniza dentro de la modernización global que han experimentado las obras.

\subsection{Materiales de prestaciones especiales}

En 1985 Jordi Bonet i Armengol, que ya no había sido discípulo de Gaudí, es nombrado arquitecto coordinador de las obras del Templo de la Sagrada Familia (ver tabla 1). Con este hecho, una nueva generación de técnicos toma el relevo en la dirección de las obras. Junto a Jordi Bonet empezaron a colaborar en el Templo otros arquitectos jóvenes. Entre ellos, Carles Buxadé, Joan Margarit y Josep Gómez Serrano que se encargaron del análisis estructural de las naves interiores. Dos hechos simbolizan los cambios que han ocurrido desde entonces: el aumento de los ingresos que ha permitido acelerar el ritmo de las obras y la introducción de nuevas tecnologías a nivel de materiales, diseño y procesos constructivos. El objetivo principal de los últimos años ha sido la construcción de las naves (ver tabla 1 al inicio del artículo). Esto ha supuesto el levantamiento de los muros perimetrales (finalizados en 1999), las columnas y las bóvedas interiores y las vueltas del cuerpo principal, las cuales se encuentran finalizadas, trabajándose en la actualidad en el transepto y el ábside (17).

Gaudí diseñó el interior a base de geometrías regladas: helicoides de doble giro para las columnas, paraboloides para las cubiertas superiores e hiperboloides imbricados con paraboloides de transición para las vueltas del techo. Como el mismo intuyó, la construcción de esta parte se ha hecho de hormigón armado. Estas bóvedas abandonan el concepto de arcos isostáticos independientes propios del gótico. Como alternativa, las bóvedas de

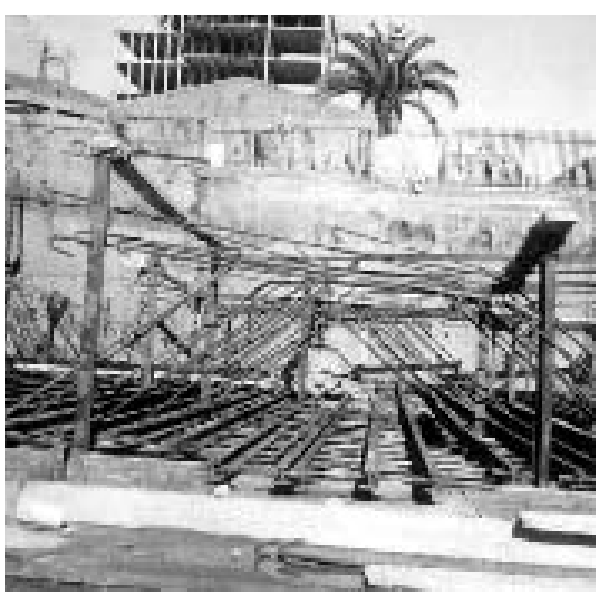

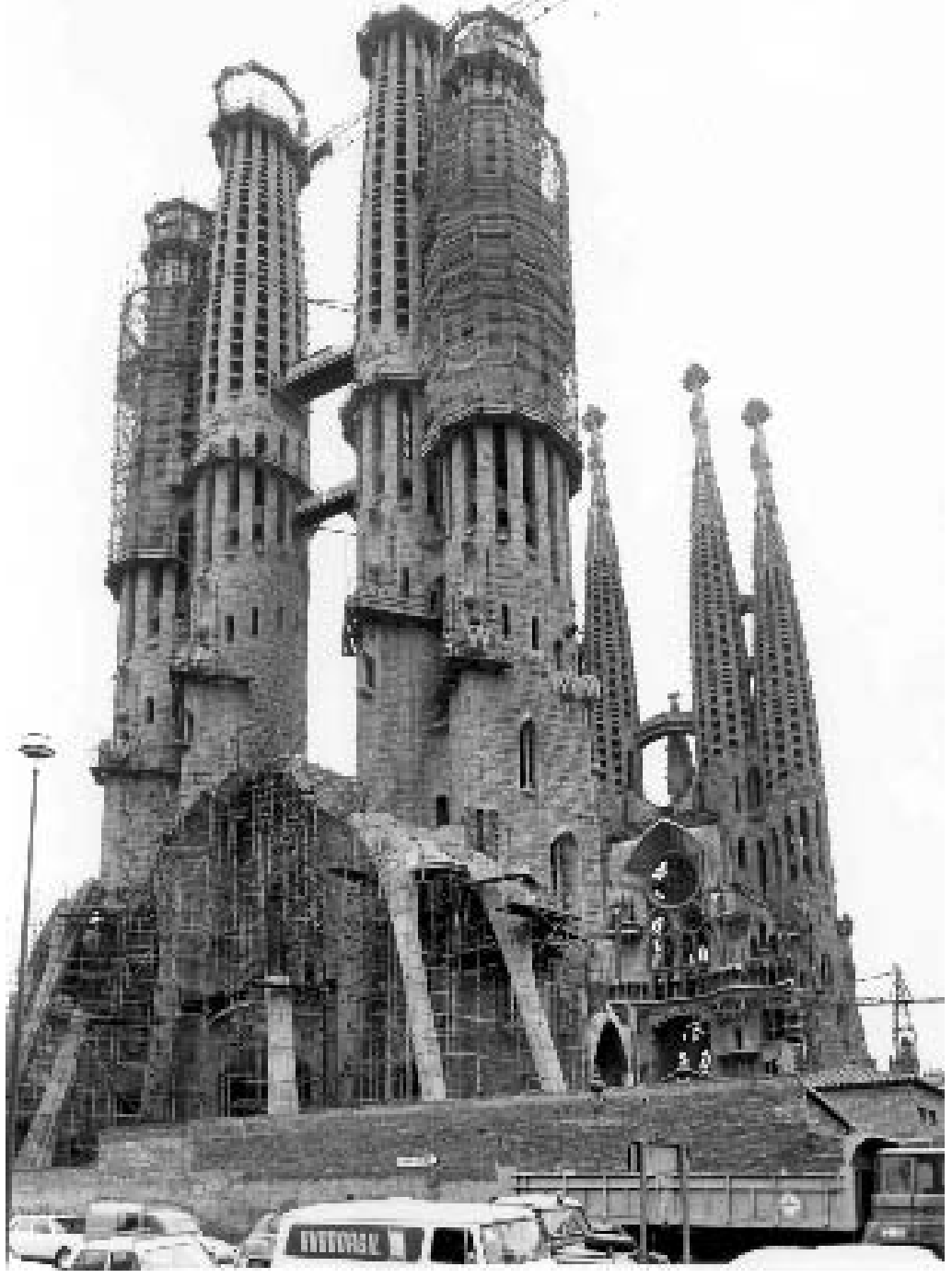

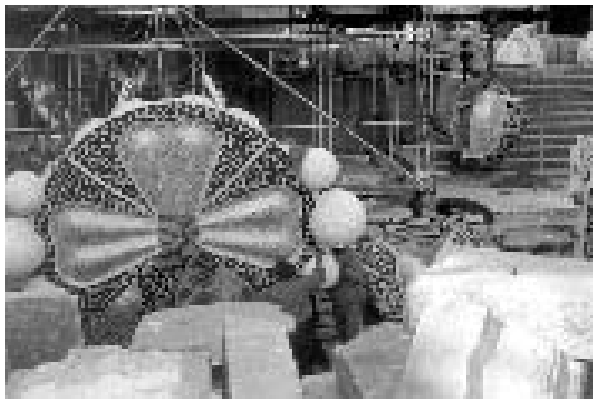

7. Construcción de las columnas de la puerta de la Fachada de la Pasión. Fuente: ATESF.

8. Raíles de RENFE utilizados en e armado de la cimentación de la Fachada de la Pasión. Fuente: ATESF.

9. Piezas de coronación de los pináculos de las torres de la Fachada de la Pasión. Fuente: ATESF. 
la Sagrada Familia son hiperestáticas, hormingonadas entre ellas y a la parte superior de las columnas para darle una unidad al conjunto que haga la estructura menos vulnerable. Así lo argumenta Domènec Sugranyes, uno de los principales colaboradores de Gaudí, en una conferencia dada en el Colegio de Arquitectos de Cataluña en 1923 titulada "la estabilidad estática del Templo de la Sagrada Familia". Es importante recordar que Antoni Gaudí murió en 1926 y que por el lugar donde fue pronunciada la conferencia no cabe interpretarla como opiniones particulares de Sugrañes sino como la exposición pública de la solución definitiva del interior del Templo:

"En este sistema, las cargas se van a sostener directamente por medio de columnas que se ramifican formando el ramaje, con objeto de ir a buscar las masas de construcción en aquellos puntos en los que podemos considerar que éstas se concentran, es decir, en sus centros de gravedad. Por eso es preciso que esas masas de construcción, que deben de ser sostenidas, formen un conjunto unido, concrecionado [hormigonado] podríamos decir. Para que los puntos de apoyo puedan reducirse, las llamada masas, cubiertas especialmente, deben estar armadas, obteniéndose así otra ventaja grandísima, la facilidad y economía de su construcción pues quedan suprimidas las cimbras y contrapesos que tanto la encarecen. En el sistema adoptado, como las superficies empleadas para la formación de bóvedas y cubiertas son superficies regladas, hiperboloides y paraboloides hiperbólicos, las generatrices y directrices que las forman serán a la vez la armadura que les dará unidad y resistencia." (15).

Pero es necesario decir, que lejos de los hormigones de principios del siglo XX, su construcción ha hecho necesario mejorar las prestaciones mecánicas de los materiales utilizados hasta el momento e incorporar los últimos avances en componentes y aditivos. Por ejemplo, las columnas de las naves del cuerpo principal, que no deberán resistir el peso de ninguna torre, se construyeron en hormigón convencional (con una resistencia característica entre los 30 y $50 \mathrm{MPa}$ ). No ocurrió lo mismo cuando se empezaron a definir las columnas del transepto sobre las que irán las torres de los evangelistas y el cimborio central dedicado a Jesucristo. Para no tener que aumentar el diámetro de las columnas, fue necesario utilizar un hormigón blanco de altas prestaciones in situ $\left(f_{\mathrm{ck}}=80\right.$ $\mathrm{MPa}$ ) en lugar del hormigón arquitectónico prefabricado $\left(f_{c k}=35 \mathrm{MPa}\right)$ utilizado en las columnas de la nave principal (18).

Las innovaciones no han sido sólo en materiales sino también en proceso. Así, por ejemplo, desde 1991 la oficina técnica del Templo utiliza el dibujo asistido por ordenador (19). De esta manera es posible definir con gran precisión los elementos geométricos y sus uniones antes de la construcción de maquetas a escala, de la misma manera que ya hacía Gaudí. En estos trabajos colabora actualmente la universidad Politécnica de Cataluña (UPC) con un equipo dirigido por Jordi Coll y con la participación de Mark Bury desde la RMIT University (Australia). Estas herramientas de dibujo se han convertido en elementos fundamentales para el desarrollo posterior de los encofrados de piezas especiales ya que reducen tiempo y costes (ver figura 10 como ejemplo). En la actualidad en la Sagrada Familia se utilizan unos 300 materiales entre los que predominan la piedra, el hormigón (5 tipos distintos) y el acero ya sea en elementos prefabricados o in situ. Para analizar algunos de los retos que hasta el momento se han salvado, es útil comprobar dónde y cuándo se ha utilizado cada material, tal como puede verse en la tabla 2 .

La prefabricación ha estado presente desde el principio en la Sagrada Familia. Inicialmente las piezas prefabricadas eran de piedra. Como se puede consultar en el apartado 3.1., estos elementos se empleaban especialmente en los exteriores de columnas y muros que eran rellenados con mampostería. En la actualidad, se sigue utilizando la piedra en las camisas exteriores de las partes bajas de las columnas y en aquellos elementos que estarán a la intemperie (como son exteriores de ventanales, etc.) así como en elementos decorativos. Estas piezas se tallan manualmente o con impresoras tridimensionales de última generación para aumentar la rapidez y la economía del proceso. En cuanto a los elementos prefabricados de hormigón, al principio se realizaban en los propios talleres del Templo y se colocaban después. Pero, desde los años setenta la falta de espacio y el gran número de elementos iguales ha hecho necesario que su fabricación se encargue a empresas externas.

Después de la finalización de las torres de la Fachada de la Pasión (1977) la piedra ha ido cediéndole terreno al hormigón, debido a la economía y a la facilidad de fabricación.

En la actualidad, aunque el hormigón sigue siendo un material económicamente más competitivo, las diferencias se han reducido (la misma pieza en piedra cuesta el doble que en hormigón cuando había llegado a ser ocho veces más cara). Es posible que en el futuro elementos que hoy se colocan de hormigón prefabricado vuelvan a hacerse de piedra, por el avance en la tecnología del tratamiento de la misma. 

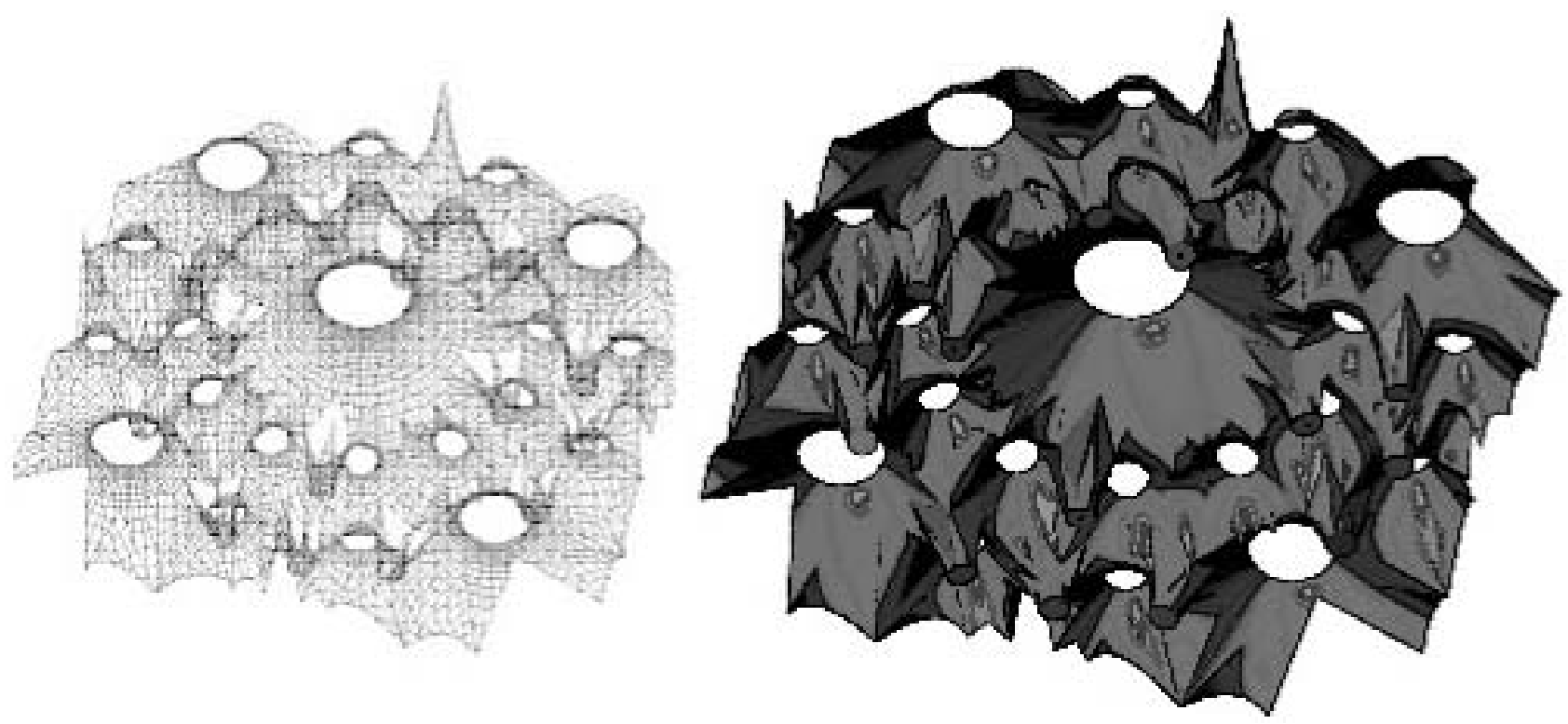

10

La mayoría de estos elementos prefabricados de hormigón forman la parte más decorativa de las obras del Templo y están realizados en hormigón blanco. Ejemplo de ello son el coro y los capiteles finales de las naves laterales o los ventanales interiores. En cuanto al resto de partes del Templo que se construyen in situ, el material utilizado mayoritariamente es el hormigón armado con diferentes revestimientos exteriores y también la obra vista recordando la bóveda catalana. En los párrafos siguientes se detalla en qué partes se ha empleado cada material siguiendo el proceso de elaboración del diseño definitivo descrito a continuación.

1. Investigación y análisis de la información existente del proyecto original (modelos de yeso y otra documentación), de su geometría, composición y proporciones.

\section{Dibujo informático del elemento.}

3. Ejecución del modelo de yeso del elemento dibujado, con la ayuda los últimos años de una impresora de cera y después de yeso en tres dimensiones.

4. Comparación entre el nuevo modelo y el original. Colocación del nuevo modelo en la maqueta de conjunto.

5. Corrección del dibujo y de los modelos hasta a considerarlos definitivos.

6. Elaboración del proyecto ejecutivo del elemento para su construcción.

En 1986 se empezó la cimentación del cuerpo principal del Templo y a principios de los 90 las columnas de las naves (ver figura 11, pág. siguiente). Como otros elementos anteriores se construyeron con hormigón armado.
Sin embargo, estas estructuras, sometidas al peso de las cubiertas, contenían una cuantía de armaduras muy superior a las partes de las fachadas construidas hasta entonces. Esto hacía necesario un hormigón muy trabajable. Para conseguirlo empezó a utilizarse fluidificante como aditivo para garantizar la colocación del hormigón. Desde entonces el fluidificante es un componente habitual del hormigón utilizado en el Templo (ya sea el que se trae preparado o el que se amasa en la propia obra).

Más tarde, se inició la construcción de las bóvedas de las naves del cuerpo principal.

Tabla 2

Materiales utilizados en la construcción actual de la Sagrada Familia. Elaboración propia.

\begin{tabular}{|c|c|}
\hline TIPO DE HORMIGÓN & TIPO DE ELEMENTO \\
\hline $\begin{array}{l}\text { PIEDRA NATURAL } \\
\text { (Varias Procedencias) }\end{array}$ & $\begin{array}{l}\text { - Encofrado perdido de muros y columnas } \\
\text { - Elementos decorativos }\end{array}$ \\
\hline $\begin{array}{l}\text { HORMIGÓN EN MASA } \\
\text { (fck } 25 \mathrm{MPa})\end{array}$ & - Relleno de muros y ventanales de las naves laterales y central \\
\hline $\begin{array}{c}\text { HORMIGÓN } \\
\text { ARMADO } \\
\text { CONVENCIONAL (fck } \\
45 \mathrm{MPa} \text { ) }\end{array}$ & $\begin{array}{l}\text { Elementos estructurales que deben ser armados pero no soportan grandes } \\
\text { cargas: } \\
\text { Hormigonado in situ: } \\
\text { - Columnas de las naves laterales y centrales del cuerpo principal } \\
\text { - Interior de las bóvedas de la nave central } \\
\text { - Claustro de la Pasión } \\
\text { - Fachada de la Gloria (excepto las columnas)... } \\
\text { Preparado: } \\
\text { - Cimentaciones }\end{array}$ \\
\hline $\begin{array}{l}\text { HORMIGÓN ALTA } \\
\text { RESISTENCIA (blanco: } \\
\text { fck } 80 \text { MPa, gris: fck } 60 \\
\text { MPa) }\end{array}$ & $\begin{array}{l}\text { - Columnas del crucero y transepto } \\
\text { - Columnas del ábside } \\
\text { - Ventanales del crucero } \\
\text { - Columnas de la Fachada de la Gloria }\end{array}$ \\
\hline $\begin{array}{c}\text { HORMIGÓN } \\
\text { PROYECTADO (fck } 25 \\
\text { MPa) }\end{array}$ & $\begin{array}{l}\text { - } \text { Cóvedas de las naves laterales } \\
\text { Coros }\end{array}$ \\
\hline $\begin{array}{l}\text { HORMIGÓN } \\
\text { PREFABRICADO }\end{array}$ & $\begin{array}{l}\text { - Parte superior de las columnas de la nave principal } \\
\text { - Parandillas del coro } \\
\text { - Pentanales de la escalera de caracol del ábside } \\
\text { - Capiteles superiores de las columnas cuando llegan a las bóvedas }\end{array}$ \\
\hline
\end{tabular}



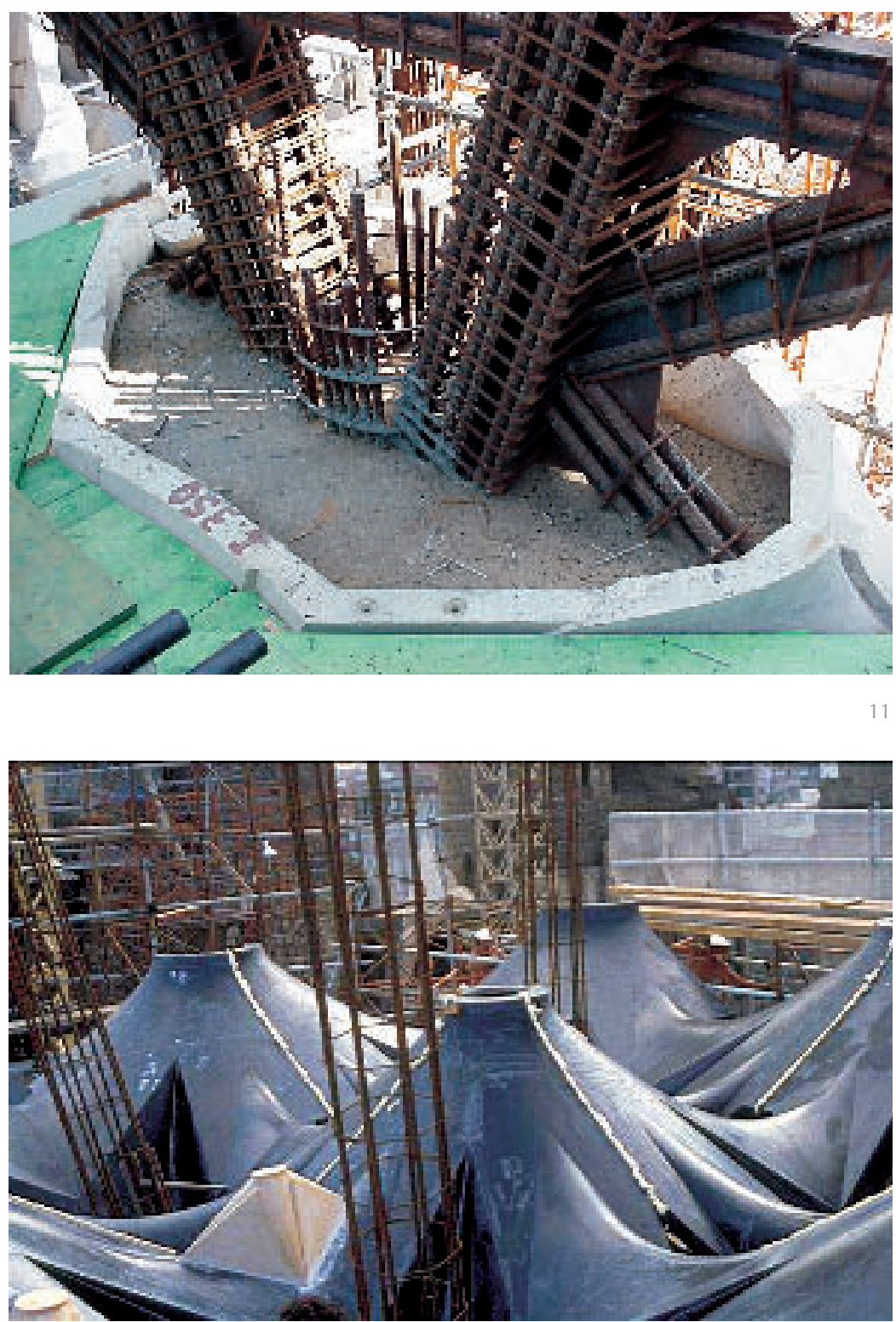

Hacia 1995 se inició la construcción de los hiperboloides que forman las naves laterales empleando hormigón proyectado. Si se hacía prefabricado, para no perder continuidad, por encima se debía colocar una losa de unión lo que aumentaba el espesor del conjunto. Era necesario, por lo tanto, hormigonar in situ, pero las paredes de los hiperboloides son demasiado verticales para poder colocar el hormigón con los métodos tradicionales sin que se deslice al fondo del encofrado (o requería de un contraencofrado con el consiguiente incremento de costes), en consecuencia, se decidió proyectar las paredes exteriores de los hiperboloides y el interior rellenarlo con hormigón vertido con cubilote y con el armado siguiendo las directrices de los hiperboloides. Para estos trabajos se utilizaron unos moldes de poliéster que pueden verse en la figura 12. En 1998 se iniciaron los hiperboloides de la nave central, los cuales se construyeron siguiendo la técnica tradicional
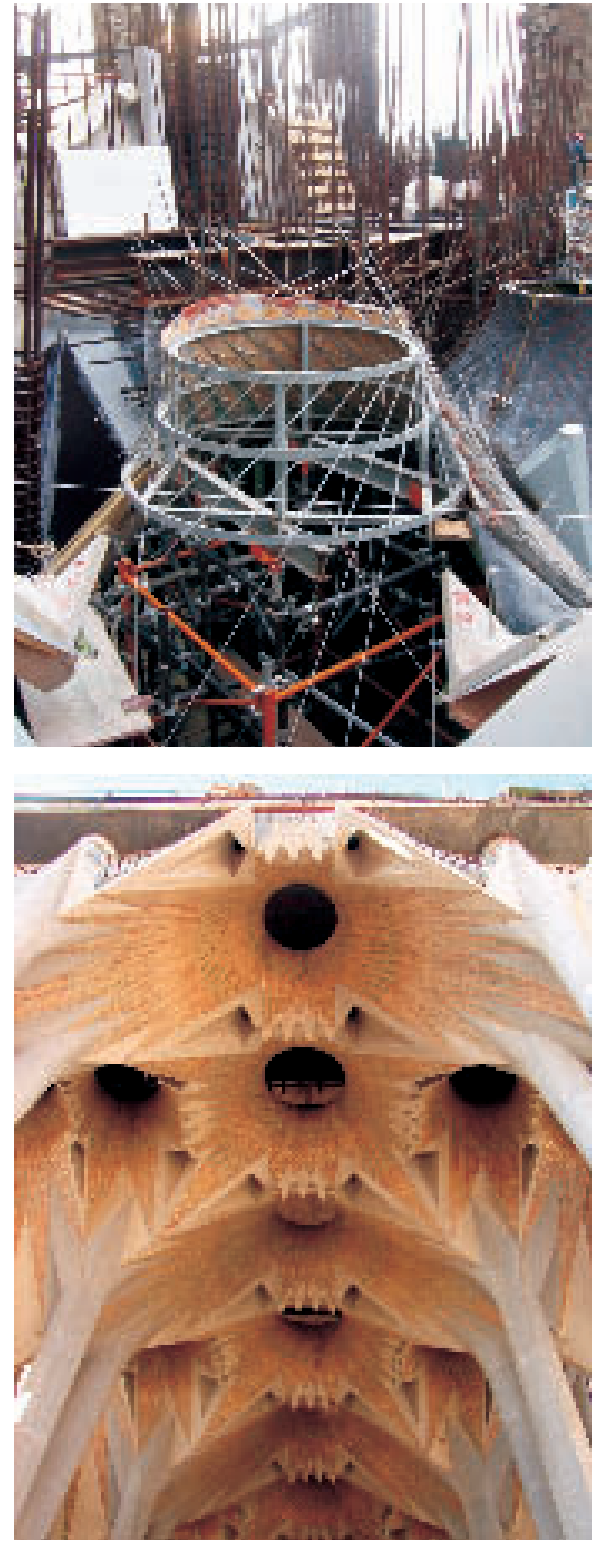

de ladrillo visto conocida como "Volta Catalana". Para ello, se preparaba el encofrado del molde con unas barras de acero recubiertas de tela metálica sobre el que se iban colocando filas de ladrillo. La primera capa sigue las directrices del hiperboloide, tal como puede verse en la figura 13. Las capas siguientes siguen direcciones diferentes para aumentar la unión entre capas. Siguiendo la evolución constructiva, desde 1998 los esfuerzos se centran en la construcción de las columnas y las bóvedas del transepto y el ábside. Las formas y los materiales siguen una coherencia con las leyes de generación de las naves del cuerpo principal (de las que se disponía de un estudio más extenso), si bien la solicitación mecánica del conjunto es mucho mayor. Al plantearse la construcción de las columnas del transepto, sobre las que se ubicarán parte de las torres de los evangelistas aparece el Hormigón de Alta Resistencia (HAR) en la obra (20). Como el 
resto de pilares de la Sagrada Familia estas columnas del transepto se ramifican a partir de un capitel elipsoidal. Por encima de este punto las camisas de piedra desaparecen y la columna se construye en hormigón visto de tonalidad blanca. Junto al cambio de forma y material, las columnas disminuyen su sección de manera que la tensión de compresión a la que se ven sometidas es mayor que en los niveles inferiores. Por esta razón se necesitaban estructuras capaces de resistir las cargas a compresión de las cubiertas respetando la forma y diámetro que ya había definido Gaudí (4). Finalmente se utilizó hormigón blanco de altas prestaciones in situ $\left(f_{c k}=80 \mathrm{MPa}\right)$ en lugar del hormigón arquitectónico prefabricado $\left(f_{c k}=35 \mathrm{MPa}\right)$ empleado en las columnas de la nave principal. La dosificación de este primer hormigón de Alta Resistencia refleja cierta influencia de la dosificación del primer hormigón de alta resistencia en España (6).

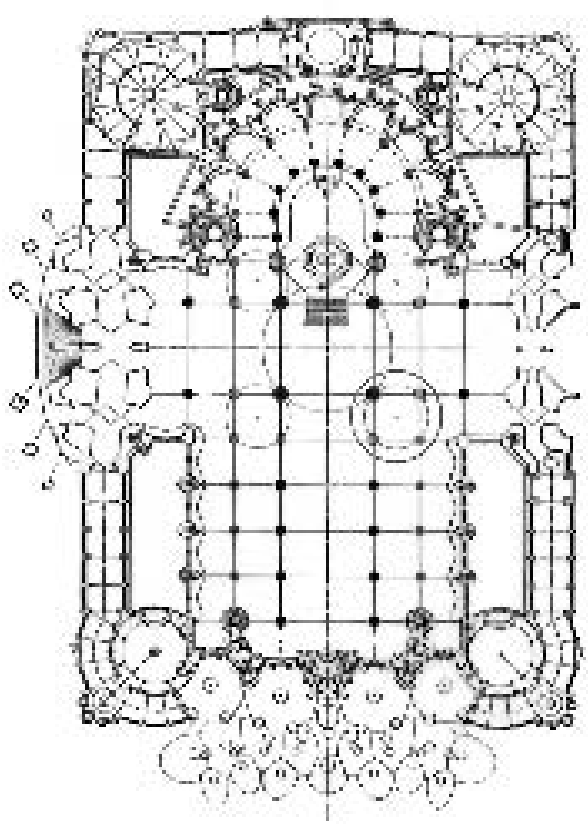

La gran innovación de este cambio fue la introducción de microsílice (blanca en este caso) en la dosificación de la Sagrada Familia. Estas columnas son uno de los elementos más importantes y singulares del Templo. Existen cuatro tipos distintos y se diferencian entre ellas en la geometría (según sea 6, 8, 10 ó 12 el número de puntas del polígono estrellado que genera su sección). También las diferencia el material empleado según la carga que deben soportan y el significado religioso que Gaudí quiso darles (ver figura 14 b). Aunque las columnas de la cripta se habían construido con camisas de piedra y rellenas de mampostería, Gaudí plantea las columnas del interior macizas. Dadas las solicitaciones mecánicas de cada parte, dedica mucho tiempo ensañar en el laboratorio de la facultad de ingenieros industriales de Barcelona la resistencia de diferentes piedras para poder escoger el material según la ubicación de cada columna. Al disponerse de otros materiales diferentes a la piedra para alcanzar estas resistencia, Ilegado el momento de la construcción de los pilares se ha recuperado el método constructivo de la cripta y el encofrado exterior de la piedra escogida por Gaudí se rellena de hormigón armado.

En la figura 14, puede verse que las columnas de diez puntas basálticas, situadas en el transepto, soportan las torres de los evangelistas de $130 \mathrm{~m}$ de altura conjuntamente con las columnas centrales porfídicas (de doce puntas) y las columnas de ocho puntas graníticas extremas de las cantorías (ver figura 14a). En la actualidad se trabaja en el centro del crucero a la cota de $60 \mathrm{~m}$ donde las cuatro columnas centrales porfídicas se unen también en la bóveda central que soportará la base de la torre principal de $170 \mathrm{~m}$ de altura, tal como puede verse en la figura 15b, pág. 18 . En ella, aparecen las bases de dos de las torres de los evangelistas más cercanas al cuerpo
14. A- Esquema de la planta de las columnas del Templo de la sagrad familia. B- Ubicación de las columnas en el Templo. Fuente: ATESF.

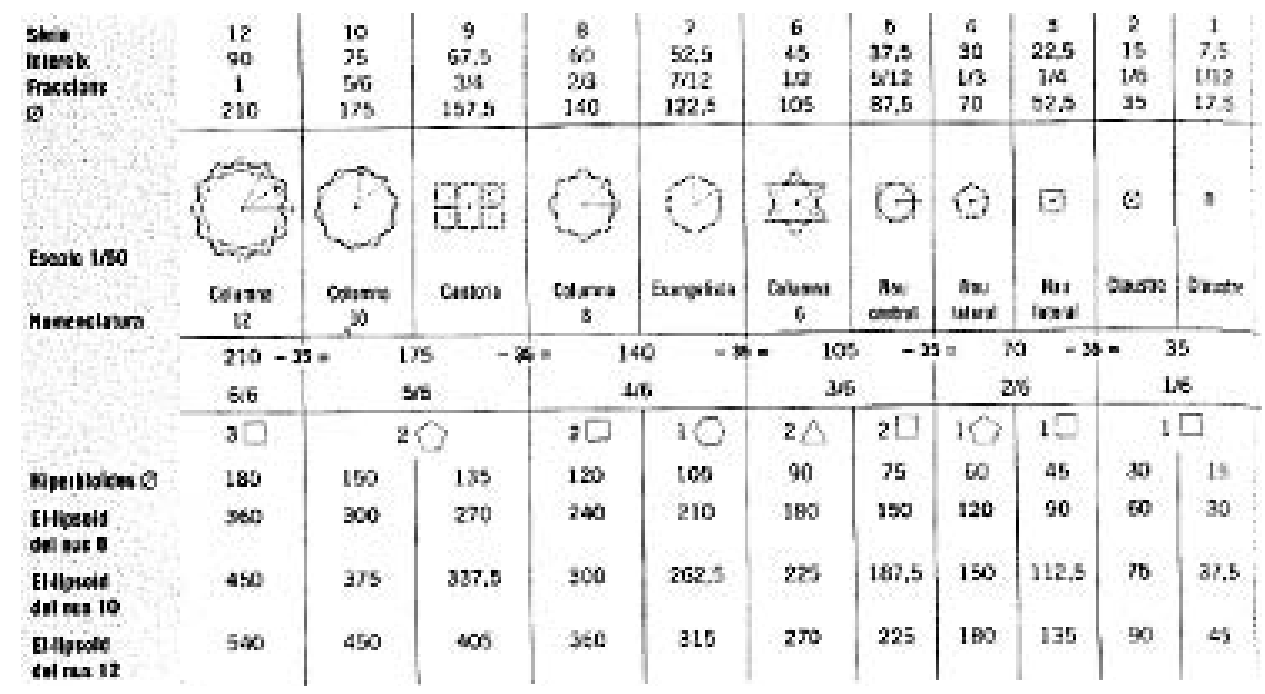




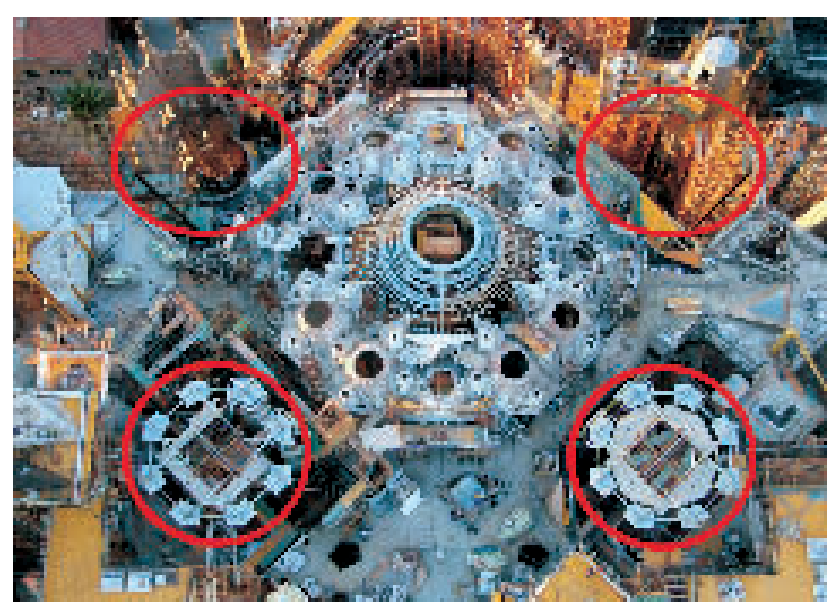

A

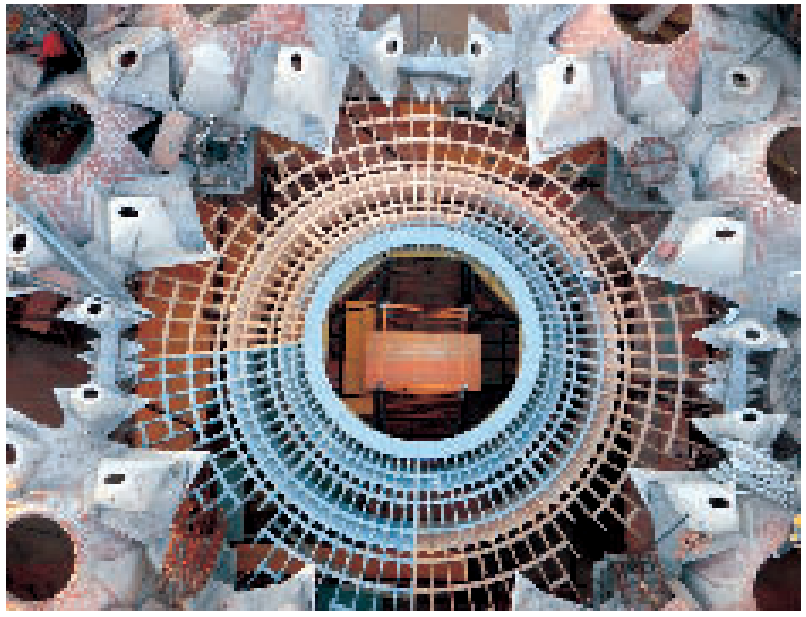

B
15. Estado actual de las obras del transepto. Fuente: ATESF. principal terminadas y el arranque de la torre principal (Figura 15a), estando algo más retrasadas las bases de las otras dos torres del lado ábside. Al enfrentarse a partir de 1999 con la construcción de estas columnas del crucero, y una vez aprobado el HAR blanco introducido en la Sagrada Familia en 1998, se varió también la composición de los otros hormigones utilizados dando como resultado las dosificaciones de la tabla 3. De esta forma se pretendía optimizar los materiales empleados para alcanzar las prestaciones técnicas necesarias. Los valores medios de las resistencias a compresión del HAR, tal como es de esperar, supera la resistencia característica de proyecto en ambos tipos de hormigones (gris y blanco).

Así, la resistencia a compresión a 28 días del hormigón gris de alta resistencia era de $85 \mathrm{MPa}$ (con un $\mathrm{f}_{\mathrm{ck}}$ de proyecto de $60 \mathrm{MPa}$ ) y en el caso del blanco, la resistencia era de $98 \mathrm{MPa}$ (con un $\mathrm{f}_{\text {ck }}$ de proyecto de $80 \mathrm{MPa}$ ). Hay que destacar la importancia del empleo de la microsílice en este aumento de las resistencias, pudiéndose reseñar, que en el caso del hormigón blanco, el humo de sílice es blanco para conseguir la tonalidad adecuada. Por otro lado, una de las exigencias más limitativas para la dosificación del hormigón en la Sagrada Familia era, y es, la de la trabajabilidad durante la puesta en obra. Como ya se ha mencionado, la existencia de secciones muy pequeñas ya definidas (columnas de diámetro limitado, etc.) hace que la mayoría de las estructuras de hormigón armado del Templo presenten una cuantía muy elevada de armaduras.

Esto hace necesario un hormigón muy fluido para que la pasta se introduzca correctamente sin que se creen coqueras. Para que el hormigón sea puesto en obra debe tener un cono de Abrams entre 27 y $28 \mathrm{~cm}$ (lo que supone un valor del cono muy elevado) sin disgregaciones. De hecho hasta el momento presente no se han realizado aplicaciones de hormigón autocompactante, que podría ser una alternativa, si bien en la actualidad se está iniciando esta línea. Esta consistencia no se puede alcanzar aumentando la cantidad de agua de la dosificación porque eso haría perder resistencia al hormigón. En su lugar, utilizan super fluidificantes de última generación, fijándose la dosificación del aditivo en el momento de amasado. La dosis empleada desde 1999 oscilaba alrededor de los 15 litros $/ \mathrm{m}^{3}$, lo que representa el $3,2 \%$ con respecto a la cantidad de cemento, el cual es un valor alto con respecto al recomendado por el fabricante (entre el 0,7 y el 2,6\%). La Sagrada Familia también necesitaba un hormigón con garantías de durabilidad, sobre todo el colocado en las partes que resisten las mayores cargas.

Esto implicaba reducir la porosidad del hormigón una vez endurecido para hacerlo más resistente frente al ataque de los agentes externos. Para ello se actuó sobre la cantidad de finos de la dosificación, contando entre ellos con la contribución de la microsílice. En el contexto de la tesina de especialidad de Rosa Grima para la Escuela Técnica Superior de Ingenieros de Caminos, Canales y Puertos de Barcelona (UPC) titulada "El Hormigón en el Templo de la Sagrada Familia" (21) y en consenso con el equipo técnico de la Sagrada Familia, durante el 2003 se propuso un reajuste en la dosificación para conseguir la fluidez necesaria reduciendo la cantidad de fluidificante y ajustando la relación áridos/cemento en aras a conseguir las prestaciones mecánicas y de durabilidad requeridas.

Aunque inicialmente se plantearon diferentes alternativas de dosificación, se optó por la dosificación dada en la tabla 4, en la cual se redujo el aditivo hasta un 2,6\% y se aumentó la relación grava/arena, no permitiéndose reducir el contenido de ce- 
mento, por la propia idiosincracia de la obra. En las pruebas, realizadas en condiciones de verano, se obtuvo un asiento medido en el cono de Abrams de $27 \mathrm{~cm}$, que cumplía los requisitos de trabajabilidad buscados. Las resistencias medias obtenidas a 9 días fue de $80,455 \mathrm{~N} / \mathrm{mm}^{2}$ mientras que a los 28 días fue de $87,66 \mathrm{~N} / \mathrm{mm}^{2}$, que superaban los valores requeridos, por lo que se aprobó el cambio. En la actualidad, los esfuerzos de la obra se centran en el cierre de los $4.500 \mathrm{~m}^{2}$ que forman el espacio interior del Templo, centrándose en las columnas y cubiertas del crucero con el arranque de las torres centrales (ver figura 15).

En los próximos meses se focalizarán en el ábside (ver figura 16) donde se han acabado las vueltas del deambulatorio a $30 \mathrm{~m}$ de altura y se trabaja en la corona circular que rodea el centro del ábside a 45 y $60 \mathrm{~m}$ de altura para concluir el espacio a $75 \mathrm{~m}$ de altura con una vuelta formada por un gran hiperboloide. Se pretende tener las cubiertas acabadas en el año 2010 y así poder iniciar nuevos elementos. Una vez analizadas las últimas modificaciones introducidas en los materiales del Templo, es necesario destacar que el espíritu de las obras sigue siendo el mismo. La modernización de los últimos años no ha hecho perder el carácter personal que siempre ha tenido la Sagrada Familia.

La Junta Constructora, continuadora de la que en su día inició el proyecto, coordina la obra que luego dirige el equipo técnico con el mismo espíritu de trabajo personalizado que tenía Gaudí.

El reto más importante a afrontar en el futuro es la construcción de las torres sobre el crucero y el ábside. Estos elementos conjugarán la construcción más tradicional (con partes de ladrillo visto) y los materiales más avanzados buscando máxima ligereza y resistencia.
Tabla 3

Dosificaciones del hormigón utilizado en la Sagrada Familia a partir de 1999. Fuente: ATESF.

\begin{tabular}{|l|c|c|c|c|c|c|}
\hline & \multicolumn{2}{|c|}{ HAR } & H. CONVENCIONAL & \multicolumn{2}{c|}{ H. MASA } \\
\hline \multicolumn{1}{|c|}{$\mathrm{Kg} / \mathrm{m}^{3}$} & $\begin{array}{c}\text { GRIS } \\
\text { H-600 }\end{array}$ & $\begin{array}{c}\text { BLANCO } \\
\text { H-800 }\end{array}$ & $\begin{array}{c}\text { GRIS } \\
\text { H-450 }\end{array}$ & $\begin{array}{c}\text { BLANCO } \\
\text { H-450 }\end{array}$ & $\begin{array}{c}\text { GRIS } \\
\text { H-250 }\end{array}$ & $\begin{array}{c}\text { BLANCO } \\
\text { H-250 }\end{array}$ \\
\hline Cemento I 52,5 & 475 & & 475 & & 350 & \\
\hline Cemento blanco & & 475 & & 475 & & 350 \\
\hline Árido calizo 5-12 mm & 1100 & 1100 & 1100 & 1100 & 1100 & 1100 \\
\hline Arena silícea 0,3 mm & 700 & 700 & 700 & 700 & 800 & 800 \\
\hline Microsílice & 30 (gris) & 30 (blanco) & & & & \\
\hline Superfluidificante & $9-15$ & $9-15$ & $8-12$ & $8-12$ & & \\
\hline Agua & $110+40=150$ & $110+40=150$ & $180+40=220$ & $180+40=220$ & $180+40=220$ & $180+40=220$ \\
\hline PRECIO $(€)$ & 90 & 173 & 55 & 100 & 48 & 84 \\
\hline
\end{tabular}

Tabla 4

Propuestas de ajuste de la dosificación del hormigón utilizado en la Sagrada Familia. Fuente: (21).

\begin{tabular}{|l|c|c|}
\hline & $\begin{array}{c}\text { Sagrada } \\
\text { Familia H- } \\
600 \text { gris }\end{array}$ & PROPUESTA \\
\hline Cemento $\left(\mathrm{Kg} / \mathrm{m}^{3}\right)$ & 475 & 475 \\
\hline Grava $(5-12)$ & 1100 & 1030 \\
\hline Arena $(0-5)$ & 700 & 800 \\
\hline Microsílice & 30 & 30 \\
\hline Agua $\left(1 / \mathrm{m}^{3}\right)$ & 150 & 150 \\
\hline superfluidificante & 15 & 12 (ajustar) \\
\hline
\end{tabular}

\section{CONCLUSIONES}

Aunque Gaudí construyó sólo una parte de la Sagrada Familia, se dedicó a estudiar la forma y las estructuras del resto del Templo dejando en sus estudios el camino a seguir por sus sucesores. La implicación personal de los colaboradores y la búsqueda de la innovación constructiva se han mantenido a lo largo de los años.

Los constructores de la Sagrada Familia, manteniendo ese espíritu innovador, han ido incorporando, a lo largo de los años, tal como se ha visto, los últimos avances tanto en mate-
16. Construcción de las vueltas laterales del ábside y de los ventanales. Fuente: ATESF.
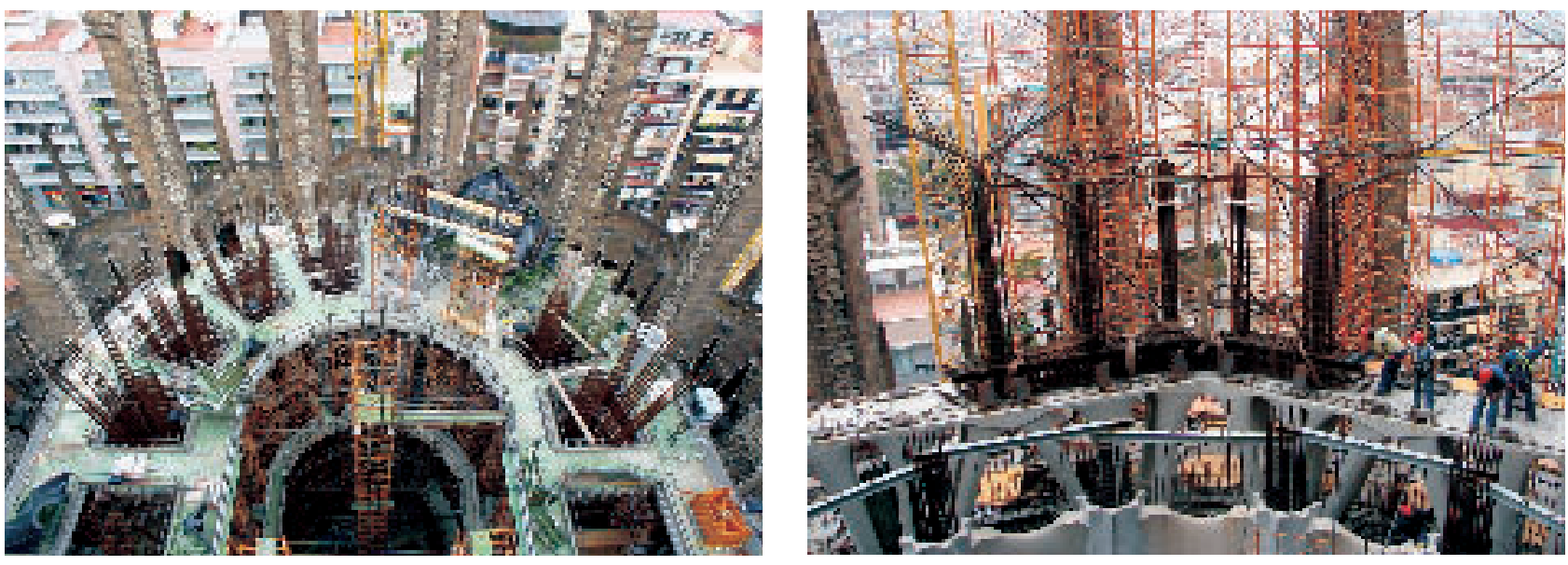
riales (HAR, aditivos, etc.), como en procesos (dibujo asistido por ordenador, maquinaria de tallado, etc.). Aunque, por diferentes motivos la incorporación de estas innovaciones ha entrado con cierto retraso en la construcción del Templo, a menudo, se ha tenido un tiempo de respuesta rápido en el momento en que aparece la necesidad.

Por poner un ejemplo, ante la necesidad de no aumentar el diámetro de las columnas del crucero aparece la solución de utilizar Hormigón de Alta Resistencia.
También es necesario destacar que este decalaje en la introducción de las innovaciones a nivel de materiales no se produce a nivel de procesos. La construcción de la Sagrada Familia ha sido pionera en la utilización de las técnicas más avanzadas de diseño asistido por ordenador.

En la actualidad el encaje de las cubiertas del ábside se realizan a través de modelos paramétricos dibujados a escala con programas de dibujo.

\section{BIBLIOGRAFÍA}

(1) Giralt-Miracle, D. et al.: Gaudí. La recerca de la forma. Espai, geometria, estructura i construcció. Ajuntament de Barcelona-Sociedad Estatal para la Acción Cultural Exterior (SEACEX) Lunwerg, Barcelona, 2002.

(2) Pla, J.: Homenots, Vol. I. Ed. Destino, Barcelona, 1969.

(3) González i Moreno-Navarro, A.: "Gaudí constructor". Informes de la Construcción, no 407 (1990), pp. 9-14.

(4) I. Puig Boada.: El Temple de la Sagrada Família. Col·lecció Sant Jordi. Ed. Barcino, Barcelona, 1929.

(5) Gómez Serrano, J.; Espel, R.; Grima, R.; Burry, M.C. and Aguado, A.: "Evolution of the formwork used in the temple of the Sagrada Família". International Journal of Architectural Heritage. Aceptado (2008). ISSN: 1558-3058.

(6) Gómez Hermoso, J.: "El hormigón de Alta resistencia en la ingeniería civil". Revista de Obras Públicas, Vol. 147, no 3397 (2000), pp. 7-31.

(7) Bassegoda i Nonell, J.: "La construcción tradicional en la arquitectura de Gaudí". Informes de la Construcción, n 407 (1990), pp. 6-9.

(8) Cañadas, J.E.: Noticia del formigó. Recopilació d'apunts històrics en el 25 aniversari d'anefhop-Catalunya 1981-2006. Ed. ANEFHOP Catalunya, 2006.

(9) Cañadas, J.E.: Factores que influyen en la prognosis de la resistencia a compresión del hormigón. Estudio efectuado a partir de las materias primas y condiciones de Cataluña. Tesis doctoral, E.T.S. Arquitectura de Barcelona. U.P.C. Directores: Juan MARGARIT y Antonio AGUADO, 26 de Junio de 1989.

(10) Espel, R.: Trabajo Final de Carrera. Escola Politécnica Superior d'Edificació de Barcelona, UPC, 1993.

(11) Bergós Massó, J.: Materiales y elementos de construcción, estudio experimental. Ed. Bosch, Barcelona, 1953.

(12) Bassegoda, J. y Amigó. Conferencia p. en Anuari de l'asociació d'arquitectes de Catalunya, 1925.

(13) Carbonell de Massy, M.: Informe sobre los ensayos realizados en unas muestras de mortero de la fachada del nacimiento de la Sagrada Familia emitido por el laboratorio Lend Consulting, Barcelona, 1997.

(14) Matamala, J.: Antoni Gaudí, mi itinerario con el arquitecto. Ed. Claret, Barcelona, 1999.

(15) Sugranyes, F.: Disposició estática del Temple de la Sagrada Familia. Anuari de l'asociació d'arquitectes de Catalunya, 1923.

(16) Rafols, LI.: Gaudí. Ed. Canosa, Barcelona, 1929.

(17) Grima, R.; Gómez Serrano, J.; and Aguado, A.: "The Use of concrete in Gaudi's Sagrada Familia". Internacional Journal of Architectural Heritage, Vol. 1 n $^{\circ} 4$ (2007), pp. 366-379. doi: 10.1080/15583050701476630

(18) Buxadé, C.; Margarit, J.: "El hormigón en la arquitectura: aplicación a la construcción de la Sagrada Familia". Cemento-Hormigón, no 826 (2001), pp. 730-740.

(19) Gómez Serrano, J.; Coll i Grifoll, J.; Melero Sánchez, J.C. y Burry, M.C.: La Sagrada Familia: de Gaudí al CAD. Edicions UPC, Barcelona, 1996.

(20) Gómez Serrano, J., "El hormigón de Alta Resistencia en el Templo de la Sagrada Familia de Barcelona". Cemento-Hormigón, no 826 (2001), pp. 717-729.

(21) Grima, R.: El hormigón en el Templo de la Sagrada Familia. Tesina de especialidad ETSECCPB, UPC, 2004. 